\title{
PROGRESS IN UNDERSTANDING CLEAN METAL PRODUCTION FOR IN718
}

\author{
A. Mitchell \\ Dept of Metals and Materials Engineering \\ University of British Columbia \\ Vancouver BC Canada V6T 124
}

\begin{abstract}
$\Lambda$ bstract
"Clean metal" has always becn a description which depends on testing techniques - fundamentally, "clean" is a function of how hard we search for inclusions. The result of this situation has been a confused sequence of development in which application, test methods and refining technology have all advanced together but along different paths, often with different goals. The situation is further complicated by the properties of the alloys concerned, which determine the size range of inclusions deemed harmful in any specific application. In order to rationalize these factors, it has becn proposed that "clean" means that the mechanical behaviour of a component can be predicted from a routine examination of the microstructure, without the prospect of premature failure duc to random inclusion defects. The progress which we have made in towards this objective is the focus of this work.

The inclusion population of an alloy is made up of exogenous inclusions and indigenous ones. In the case of titanium alloys, the former has given rise to most concern whilst in the superalloys the latter provide the most of the defect sites. EB used as hearth melting has been the centre of development for the elimination of both these types of defect, with the separating capacity of the hearth used for exogenous inclusions, and also for the chemical reactions necessary to control indigenous types. The physico-chemical basis for both of the reaction systems in EBCHM is discussed with particular reference to IN 718, also in the context of the present melting and remelting techniques.

We conclude that EBCHM systems offer the best potential for making superalloys which are clean, for use in critical components in many fields of application. It remains to be seen whether or not the added cost of the process can be justified by the security and lifetime engineering savings which are brought by this new class of alloys.
\end{abstract}

\footnotetext{
Superalloys 718, 625, 706 and Various Derivatives Edited by E.A. Loria

The Minerals, Metals \& Materials Society, 1994
} 


\section{INTRODUCTION}

The requirement for clean superalloy production has been driven to a large extent by the development of fracture mechanics analysis of component behaviour in highly-stressed applications. The need to remove large extraneous particles from the alloys had been instinctively recognized for many years before the advent of fracture mechanics, but when the more sophisticated technique came into use as a predictive tool, it was realized that the available power of the method could only be used if we had a thorough understanding of the inclusion distribution in the material. The simplest way to ensure that the fracture analysis is based on a correct distribution is to remove all inclusions in the size range which will affect the analysis. This situation has been the aim of all recent developments in clean melting techniques in many alloy systems.

The above aim is a correct objective, but soon becomes lost in the attempts to define what is the permissible size and distribution of inclusions -- and in the case of very clean alloys, how to detect and verify that distribution, to an extent acceptable to the enduser. The recent past development of clean melting is a tangled web of advances in melting techniques themselves, advances in defect detection technology and a tightening of user specifications. Always in this scheme we can identify the theme of a melting advance offering the hope of better cleanness, followed by a tightening of the specifications to reflect that hope, followed in turn by a compromise between the two based on the reality of reliable quality assurance through defect detection. The ultimate aim of assuring freedom from inclusions through sophisticated process control (the "zero defect" philosophy), has so far eluded the melting processes, at least to the extent that the enduser will accept it. Unfortunately, the present state of clean melting is still controlled by the product inspection process, and the limits of alloy use are still determined by the reliability of ultrasonic testing.

The core of the testing problem is a two-part issue. First, we have the problem of the detectability of small inclusions in any given section and microstructure -- and its interplay with the statistics of detection probability. Second, and more troublesome, is the question of the detection probability for very rare defects i.e. the probability of detecting a large particle occurring at perhaps 1 in $106 \mathrm{~cm} 3$, particularly when the particle falls within the detectable size range, but not within the $100 \%$ reliable statistical range of the testing system. Given the exigencies of application in critical parts, this reliability is frequently insufficient for end-user confidence. It is this latter feature which is probably the most important driving force for higher cleanness quality in most alloys at present, in particular for disk applications with alloys IN718 and IN 706. Process development is driven by the idea that the very rare large defect can be prevented by arranging the process so that all of the product is extremely clean. Much more so, in fact, than would be required by the basic properties of the alloy and application.

An excellent illustration of the above feature may be found in the requirements for superalloy IN718 in rotating part use. The CAA criterion for "retirement-for-cause" in HPT disks is the presence of a crack which is more than $750 \mu \mathrm{m}$ in length (1). The original 
manufacturer's specification for the material comprising the disk is that it should not contain an inclusion of length greater than $250 \mu \mathrm{m}$ (which is also the limit of detection by UST in the initial billet size), and in fact the alloy as assessed by random surface metallography would show an inclusion size distribution which had a maximum size of less than $25 \mu \mathrm{m}$. Fracture mechanics computations indicate that the critical defect size at room temperature in this alloy is $250 \mu \mathrm{m}$, and obviously the CAA requirement represents the limit tolerable in view of the known crack-growth rate in the component. However, given the typical size of a large disk relative to the size of the starting ingot weight from which it has been made, we can see that one defect/ingot (a concentration of approximately $1 / 106 \mathrm{~cm} 3$ ) in the $>250 \mu \mathrm{m}$ size range could give a $10 \%$ probability that in any given disk there is a "large" defect. In principle, this defect size should be rejected by ultrasonic examination, but it is an unfortunate fact that many of the inclusion-related failures in rotating parts such as this one originate at inclusions which are in this range of size. The idea that isolated, rare occurrences of large particles can be eliminated by arranging melting conditions so that the "typical" size range of inclusions is below $25 \mu \mathrm{m}$ is probably not correct. This may be readily seen from many literature reports on fatigue and fracture properties which show a significant property dispersion even in so-called clean materials. In addition, we may see the same effect in operation upon examination of fracture origins in these materials, since the metallurgically-caused ones still predominantly occur at inclusion sites, even in the clean alloys. The true "clean" alloy has clearly not yet been achieved, in which all of the fracture origins would be at metallographic structural features, and none at inclusion sites. A recognition of this fact is central to understanding the development of clean melting processes. To appreciate the context of the present situation and its problems, we must review how the various process have evolved over the past decade, and what is their present status in producing clean superalloys, with particular reference to the rare, random large inclusions.

\section{CLEAN MELTING FOR IN718 AND OTHER SUPERALLOYS.}

The two remelting processes which are generally used for these alloy systems are ESR and VAR, preceded by a variety of primary melting steps depending on the alloy and application. The initial justification for the VAR step was one of refining capability in regard to the inclusion content left in the alloy after the primary melting, usually by VIM. Unfortunately, it was only after a long history of specification building that it came to be recognized that VAR is a process which selectively accumulates many small inclusions into a few large ones, hence rendering the average sample much cleaner than the starting alloy, but leaving a dangerous distribution consisting of a few very large inclusions to be selectively removed following ultrasonic examination. The definition of this situation is only now beginning to be detailed as the new techniques of bulk inclusion analysis ( EB and ISM button melting) are used. (It may be noted that the traditional method of chemical extraction from the bulk is not well suited to most superalloys because of the carbide content, which requires very selective dissolution in order to separate it from the oxide and nitride content). Examples in the literature are to be found for superalloys (2) and for stainless steels (3), and more will certainly appear in the future. 
As primary melting methods have improved, for example with the application of filtering and an improved understanding of the role of the refractory container, the role of the VAR process has become less that of refining and more that of a solidification control tool. Indeed, many literature reports cite inclusion distributions for bearing steels and high-strength construction steels $(4,5)$ made by air-melting techniques which are better than the specification requirements for the VAR remelted superalloys. The need for secondary remelting has been seriously questioned in the literature on this basis, but as far as can be determined, no specification has been down-graded from remelt to primary melt only on the basis of this evidence, probably out of the correct suspicion that the occurrence of rare large inclusions is somewhat greater in primary product than in remelt, for reasons which will be given below.

The ESR process has had a chequered history of development for the specialty alloy applications. It clearly has a greater capacity to remove large inclusions than has VAR (2), but at the expense of introducing a denser distribution of small inclusions (6) through the Thermochemistry of reactions between the alloy and the slag. The VAR process has an inherent mechanism for total oxygen or total nitrogen removal, but ESR does not; instead it will produce equilibrated compositions. The ESR process will produce an alloy which is at the oxygen or nitrogen potential of the slag/metal system, and these values are almost invariably higher than those pertaining to a good vacuum system. The $\mathrm{O} \& \mathrm{~N}$ contents of the alloy will, however be in solution in the high temperature region of the process, subsequently precipitating as the temperature reduces towards the liquidus/solidus region. The result is an alloy which has a higher oxygen content than would be the case in VAR, but which is cleaner, provided that an appropriate assessment method is used (7). This latter proviso has been the source of much confusion in the literature during comparisons of the relative merits of the two remelting processes. In terms of the content of inclusions in the size range which influences the properties in question, however, ESR alloys are almost certainly much cleaner than are VAR alloys.

The central question of clean melting is that of defining what level of refining represents "clean" product. For many purposes, primary melt alloy can be made with exceptionally low average inclusion levels, and if it is to be used in an application where the occasional large inclusion can be reliably detected by product testing, then elaborate schemes of remelting are not necessary, providing that initial ingot can be cast in a section which does not lead to unacceptable segregation. Examples of this condition are to be found in wire, sheet and tube applications, where the use of thin gauge product makes the testing extremely reliable. However, even in this case, it is sometimes possible to make the case for a remelting technique on the grounds of economics, since frequent rejections can escalate the product cost for example in a case where large pieces of sheet or long, un-joined tube runs are required.

We can also extrapolate this argument into the remelting processes themselves. The increased level of cleanness offered by ESR, for example, may be adequate for a particular component, without the need to up-grade the alloy by any further step such as EBCHM. In order to make a judgement on this question it is almost always necessary to 
include the variable of the specific part design since generalizations based on a particular alloy may cover a wide range of applications. In the case of alloy IN 718, for example, we may have intended uses which even in forging grades can require a very wide range of inclusion distributions, varying from ones in which ESR/VAR material is clearly acceptable to ones in which we still require added refining over that presently available in order to fully utilize the capability of the alloy, as is shown for example in Fig 1. (Equally important examples can be found in every class of specialty alloys, including those of titanium). It is in this aspect that the need for clean processing becomes unclear since in some cases it is to be justified on pure economic grounds related to yield for either the producer or the customer; in other cases it is to be justified for product reliability or design improvements in a critical part. From the standpoint of technical challenge, the latter is more interesting and it is upon this aspect that we have concentrated the effort in considering the possibilities of EBCHM.

Clean Melting Possibilities by EBCHM.

There are three basic mechanisms for removing inclusions in EBCHM; --physical separation --decomposition by vacuum reactions --dissolution in the alloy being processed.

The relative importance of these steps in any individual case depends on the Thermochemistry of the system.

The process of physical separation is comprised of both buoyancy effects and surface effects, in which the latter probably predominates in most systems involving the separation of small particles, for example oxide inclusions. As the metal melts at the inlet to the high temperature zone, the particles are rejected to the free surface by interface forces and remain there during the formation of the drops and their subsequent coalescence into the melt pool. An example of this can be seen in Fig 2 where TiN and alumina particles have been rejected to the melting surface of an IN718 bar being processed by EBCHM. It should be also noted that in this case although the residence time of the metal in the high temperature region is not great enough to dissolve these particles, all of the carbide content has gone into solution. We have found no case in the melting of IN718/625/706 where individual carbides have persisted through a conventional melting process. The creation of "rafts" of the oxide particles undergoing this process can easily be seen in an EBCHM furnace melting superalloys and is a good visual guide to the importance of feed-material preparation in regard to surface oxides as well as to the internal quality. The process is governed by the same principles as the technique of inclusion assessment by EB and has been reviewed in the literature (8). The action of surface-driven forces is strong, and accounts for the efficient separation of particles even where the buoyancy force is negative, for example the "flotation" of hafnium oxide from a superalloy. The details of this latter process are probably quite complex and must include kinetic considerations where the effect of buoyancy is minimized by the extremely small terminal velocities of the particles due to their small dimensions. Since the most of the 
particles must pass through a melting surface during the formation of the pool, the process separates a very high fraction of the second-phase oxide or nitride inclusions present at the melting temperature to the free surface at the start of the melting step. The extent to which these particles remain separated during the rest of the process determines the cleanness of the ingot. In the case of large particles, the separation efficiency is related to the magnitude of the surface forces. For oxides in superalloys, the forces are very high and all large particles are rejected to the free surface. In the case of other compositions with much smaller surface forces the buoyancy forces would predominate, but it appears that in the case of nitrides, the surface forces are still high enough to cause separation. If the particles are still contained within the liquid metal during the process their behaviour is controlled by the interaction of fluid-flow and buoyancy. This combination could lead to difficulties in achieving the required cleanness in the final product when the particle's relative buoyancy is close to zero, but is fortunately not the case with inclusions commonly found in the superalloys. It is noteworthy that the same effects which cause retention and agglomeration of particles in the VAR process are the same ones which lead to efficient separation in EBCHM.

The roles of dissolution and decomposition in removing inclusions, or in reducing their size is quite complex in all of the processes considered, but especially so in EBCHM. The indigenous inclusions, by definition, have a solubility in the alloy being processed and given the correct regime of time and temperature will return to solution following the appropriate solubility product. The way in which this effect controls the presence of nitride inclusions in superalloys, and of oxides in steels has been described (9), and the methods of calculation or experimentation required for a definition of the composition changes taking place have also been investigated. In the ideal EBCHM system, the combination of solubility and physical removal should ensure that as the alloy flows into the ingot, it contains no solid inclusions and has a content of nitrogen or oxygen which is at or below the saturation solubility at the liquidus temperature. If this situation has been achieved, any inclusions which are precipitated during the freezing process will be small, in terms of their mechanical effect on the product; the small inclusions will have had minimal chance to agglomerate during their lifetime in the liquid phase and the alloy will be clean within the definition given above. Following this approach, remarkable improvements have been made in the behaviour of these alloys (10) and more may be anticipated in the future.

It is interesting to note that the precipitation of the inclusions during cooling and freezing follows a very complex process. The oxide inclusions precipitate first, and act as nucleating sites for the subsequent nitride precipitation. TiN particles which are precipitated at an early stage of solidification always contain oxide nuclei, whilst those precipitated nearer the solidus temperature do not. The nitride particles in turn act as nuclei for primary carbide precipitation, and in IN718 the NbC particles which have formed above the first eutectic point almost always contain nitride cores. The two compounds are mutually soluble to a limited extent and the boundary between the particles is a diffuse one containing $\mathrm{Ti}-\mathrm{Nb}-\mathrm{N}-\mathrm{C}$ phases, leading to the common term "carbonitride" for the composite particle. The remaining carbide precipitates during the 
final eutectic stages, and does not contain TiN cores. It has been found (9) that the solubility limit of TiN in IN718 at the liquidus temperature is equivalent to 38ppm nitrogen, whilst the solubility limit at the solidus is approximately $5 \mathrm{ppm}$, taking into account segregation during solidification as well as the temperature decrease. If we remove nitrogen from the alloy to levels in the range of $5-10 \mathrm{ppm}$, we observe that the primary carbide nucleation is suppressed until close to the first eutectic point. The eutectic itself is then of a different composition, higher in $\mathrm{Nb}$ and $\mathrm{C}$, which causes the formation of primary platelets of either delta or gamma" as well as the usual gamma + Laves structure, in which the Laves composition has also been altered. The platelets are probably primary delta (17) although primary gamma" has been suggested (18). EPMA studies have not shown any $\mathrm{Al}$ content in the platelets which would indicate that they are primary delta, but further extraction examination would be necessary to define the composition and structure. Whether or not these changes have a significant effect on the subsequent homogenisation and heat treatment has not been determined, but it is clear that the removal of nitride inclusions has a substantial effect on the size distribution of the primary carbides. The nitrogen contents which are commonly specified in forging grades of IN718 are much higher than the above ranges, typically in the $60-80 \mathrm{ppm}$ levels, and even after conventional EBCHM, this material will not contain nitrogen at less than $20 \mathrm{ppm}$. In the case of high purity casting master alloy, the nitrogen content may be as low as $16 \mathrm{ppm}$, but in this case also the effect is not observed.

The limitations of EBCHM in regard to the inclusion removal sequence outlined above have not been determined experimentally, nor are they easily computed from first principles given our present knowledge of the process' parameters. The problem lies in the fact that once the solid inclusions have been separated from the liquid, the removal of nitrogen or oxygen from the alloy is a process of desorption or reaction at the alloy/vacuum interface, with the accompanying mass transfer process in the liquid alloy. Since the concentration gradients are small, it is normally the latter which determines the rate and it is hence strongly related to the fluid dynamics of the hearth region. In this regard it is a distinct advantage to use starting alloys which are already as clean as possible, since the load on the EBCHM process will thereby be reduced. It seems possible that the major effect of EBCHM is not in the extreme reduction of $\mathrm{O}$ and $\mathrm{N}$ contents, but instead is in the physical separation aspect of assuring the removal of all large inclusions.

The quality assurance aspect of the above sequence has not been fully recognized and exploited by the user of superalloys and high-quality steels. The advantage lies in the fact that we can compute the critical composition (saturation solubility of $\mathrm{O}$ or $\mathrm{N}$ at the liquidus temperature) which will contain no solid inclusions at the time when the alloy starts to freeze (9). With some reservations ( connected to the fluid flow processes taking place during solidification), this composition will not contain any inclusions larger than the primary precipitates which the alloy would form on freezing. It will therefore be fully clean. More importantly it is assessable, from a QA standpoint, by a random chemical analysis and that conclusion does not carry any statistical uncertainty. The importance of this aspect cannot be overstated as regards the reliability of the product from the process, 
since in all other process for refining, the bulk analytical composition is merely a guide to quality and in no way assures the freedom from large inclusions.

The decomposition and separation processes are complicated in practice by two factors: "overloading" the system with feed alloy which has sufficient inclusion material that it fully coats the free surfaces of the melting alloy; and the role of decomposition by direct impact of the beam on the surface inclusions. Obviously, if the free surfaces are fully coated, the alloy beneath the coating will at best be at the saturation solubility of the inclusion components. For the optimum chemical results, the solid inclusions should be retained in the immediate region of the melting zone, leaving a maximum of free surface for the evaporation reactions which will further reduce the content of $\mathrm{N}$ and $\mathrm{O}$.

The reactions which will take place at the free surface are predictable from considerations of the mass transfer situation and the underlying thermochemistry of the system. Whilst nitrogen, for example will desorb as the gaseous species from the surface, oxygen is only lost through evaporation reactions which involve the formation of volatile oxides. Such species may be $\mathrm{CO}, \mathrm{SiO}$ or sub-oxides of aluminium etc., and comprise the same reactions as those found in other vacuum deoxidation processing. Although IN718 has a large content of reactive element and is at a low oxygen content, the principal component of the gas evolved on vacuum reaction of the melt is $\mathrm{CO}$, and significant vacuum deoxidation can take place The higher vacuum regime of EBCHM influences the equilibrium in desorption reactions, but since the rate is almost always controlled by liquid-phase mass transfer, slight differences in ambient oxygen potential between furnace opcration modcs probably do not have a strong influence on the final product oxygen content. Features such as the surface/volume ratio and temperature regime are certainly stronger factors in determining the composition changes in respect of oxygen content. The same conclusion may not be true for nitrogen, since the alloy oxygen contents are low enough that there will be significant surface coverage in nitrogen and thercforc the desorption reaction can be quite rapid, depending on the ambient nitrogen partial pressure. The thermochemistry of the various alloys intended for clean processing by EBCHM differs very widely. In the case of $\mathrm{O}$ and $\mathrm{N}$, most superalloys contain elements which substantially lower these elements' activities and so the valucs requircd for clean alloy are extremely low. The principal elements which are involved in these reactions are $\mathrm{Ti}, \mathrm{Cr}$, $\Lambda \mathrm{l}$, and the rare earths; it is unfortunate that in the alloys which most benefit from clean melting, these elements are all present in high concentrations.

Implications for Inclusion Assessment.

The most intractable issue in this field is that how to decide when a clean alloy is indeed clean. We may illustrate this problem by reference to the many studics which appear in the literature on "clean"steels, an example of which is shown in Fig 4. It will noted that the cut-off for inclusion counting occurs at a concentration of approximately $1 / 10 \mathrm{~cm} 2$, for a size of 30 microns; the distribution shown is also typical of forging-grade IN718. The cut-off concentration obviously corresponds to quite a high volume fraction of large inclusions, and to a correspondingly-high probability of finding a cluster of large 
inclusions larger than the critical size. This problem has been addressed by an extensive metallographic study on clean steel with the result shown in Fig 5. In this study the "cluster" represents a loose agglomeration of small alumina inclusions in which the interparticle distance is less than 30 microns. Here also we see that even when the metallographic assessment of a random small area is likely to be very good, there is a significant probability of finding a defect-causing cluster in the typical forging unit size. There is a clear parallel between these studies on clean steels, and the situation in the superalloys. When the alloy is quite free from inclusions, metallographic assessment cannot be used to define the quality of the alloy in regard to isolated large inclusions or inclusion clusters. Nor does the concentration of very small inclusions bear a well-defined relationship to the concentration of the rare large inclusions. The latter make only a very small contribution to the overall oxygen analysis which as a result is a poor guide to the alloy behaviour in clean materials (2). Indeed, as has been cited above, in some cases an inverse relationship can be found, for example in the bearing steels with oxygen contents around 5ppm (16).

The introduction of the $\mathrm{EB}$ button method of inclusion assessment goes some way towards alleviating this difficulty, but still contains uncertainty. We can see from the discussion of inclusion formation and removal in this work that it is possible to conduct an EB melt of IN718 in such a way as to separate all of the inclusions which are not in solution, into a single "raft" floating on the sample melt surface. There are quite substantial difficulties associated with making this process reliable and reproducible, which have been discussed in the literature (11), but the key point at issue is that of deciding how the collected inclusion raft may represent the actual inclusion distribution in the original sample. The individual inclusion size and composition may be determined from the raft analysis, but it gives no information on the spatial distribution in the sample, which is the key point in determining the mechanical behaviour.

It would appear that we have reached a situation in which we have the alternatives of limiting superalloy use at the present property/life levels relying on UST as the assessment; or increasing the property demand on the alloy by using the EBCHM process and relying on process monitoring and control to assure quality in regard to large inclusions.

\section{The Roles of VAR and ESR}

From the above discussion concerning the inclusion reactions in EBCHM, it may be concluded that this process may be used to remove all unwanted inclusion material from the alloy and therefore no other process is required. However, one of the clear disadvantages of EBCHM is that it will not change the sulphur content of the alloy being processed. IN718 is particularly sensitive to contamination from sulphur with the result that the hot-workability is a sensitive function of S content (14), especially when the alloy is in the near-ingot condition. Although many alloy specifications accept sulphur contents in the range $10-30 \mathrm{ppm}$, there is a continuous improvement in properties as the sulphur content is lowered to the limit of chemical analysis, approximately $2 \mathrm{ppm}$. This 
very low sulphur level can only be obtained in a melting process which contains an active de-sulphurisation step.

Desulphurisation has been brought to a fine art by steelmakers, who now routinely produce very large heats of low-cost steels with sulphur contents at a few ppm. The techniques which they use are not directly applicable to IN718 or its derivatives because the alloy's reactive element content precludes the use of air melting techniques. The methods can be used on the base composition without the reactives, provided that stringent precautions are taken to exclude nitrogen pick-up during casting. Melters have developed this approach using both AOD and variations of the familiar ladle refining techniques, followed by a VIM treatment during which the reactive element content is added and controlled. Particularly when the charge is required to contain a high fraction of scrap, this method is very effective in producing a low sulphur content. It carries, however, a high risk of slag entrainment from the airmelt into the VIM, and also has great difficulty in maintaining a sufficiently-low nitrogen content, since the "base composition" has a high chromium content and rapidly absorbs nitrogen from air. The fluid slags entrained into the VIM step are particularly hard to remove and are not extracted by filters. They are a potential source of serious contamination if carried into a subsequent, and final $V \Lambda R$ melt. For many non-aerospace applications, however, the solution is to apply a subsequent ESR process, which will remove the entrained slag and also accomplish the required level of solidification control. In uses where this route is not permitted, the triple-melt variation would attain the same objective. This latter approach also can be used to remove any residual slag entrainment resulting from the practice of lime desulphurisation in VIM. By using the above approaches it appears that the production of IN7 18 at ultra-low sulphur should not be a difficult or expensive operation.

The function of sulphur in the property determination of IN718 has been the subject of much research $(12-15)$. Discrete sulphides are only found in alloys where the sulphur content is at an unacceptably high level and are not found in normal commercial alloys. For many years an addition of magnesium has been specified to "balance" the sulphur content purportedly by precipitating $\mathrm{MgS}$ inclusions, which subsequently float out of the liquid -- a reaction mechanism which has not been substantiated by cxperiment (12) at the low sulphur levels usually found in industrial melts. Instead, it seems probable that the function of the magnesium is to precipitate $\mathrm{MgS}$ inclusions at a very late stagc of solidification, possibly even after solidification, on the primary-grain boundaries. Thes inclusions are very stable during any subscquent heat-treatment, and prevent the sulphur content from forming a monolayer of NiS or $\mathrm{MnS}$ on the boundary, thus causing the difficultics in hot working. The thermochemistry of the $\mathrm{Mg} / \mathrm{S} / \mathrm{MgS}$ system suggests that this precipitation can occur, even in the very low $\mathrm{Mg}$ and $\mathrm{S}$ contents observed, due to the extensive segregation on freezing. It is possible that the rare-earth elements would have the same result, but they present an even greater difficulty in control than does $\mathrm{Mg}$.

It appears that the IN718-type alloys all require primary processing which will give sulphur contents at least below 5ppm, for optimum properties; further that the desulphurisation options require an ESR or EBCHM step before the final ingot is made, or as the final melting process, to ensure adequate freedom from oxide slag entrainment. 
One could conclude from this logic that the ideal melting sequence for IN718 would be primary desulphurisation in air followed by hot-charged VIM, casting and EBCHM.

\section{Future Perspectives for Clean Melting}

As with any other developments in alloy preparation, clean melting processes must fit into the framework of user requirements. As has been stressed above, there is little point in expending effort to produce a very clean alloy if it not required by the application. Equally important, but less-well understood is the point that focusing process development on improving average cleanness, without attention to the statistics of rare, random large inclusions is a direction fraught with hazard. Instead, process development in making clean IN718 should be directed to the removal of those inclusions which affect the properties in question; and to the development of process control which can assure the user that these inclusions have certainly been removed.

Over the immediate past period, the producer has concentrated on improving existing processes, relying on conventional methods of inclusion assessment to evaluate the improvement sequence. A high degree of success can be claimed for this procedure and the alloys presently available probably represent a quality close to the limits which can be expected from the VIM/VAR/ESR and/or VAR routes in the superalloys. Such problems as still occur are more the result of control breakdown, or ill-advised economies than the failure of the processes in principle. The user requirements have shifted in the same time frame to take advantage of the clean alloy offered so that the two systems are presently quite closely in balance e.g. user demands on IN718 are at the limits of what is commercially available from the present processes.

Future progress will probably take place only where it is initiated by the end-user since it will certainly require new process equipment and techniques, not merely a further fine-tuning of the present system. As has been described above, inclusion removal in IN718 is a complex process, but it can safely be assumed that a properly designed EBCHM furnace can produce alloy in the composition ranges which are computed to contain zero inclusion content in the solidifying region. The possibilities which this system presents are exciting and have long-range implications. The most obvious place for testing the technique lies in application to thin wire or sheet, where such an alloy would be readily evaluated. The more general application to high-quality superalloys depends on two factors; first the value of reproducibly-high properties to the user, and second, his willingness to accept process control as an evaluation rather than product testing. To a certain extent this has already occurred in titanium alloys, but is not yet evident in the superalloys.

The EBCHM process has some very strong advantages in respect of process control, partly in the nature of the heating system, and partly in the visibility of the liquid metal being processed. The electron energy may be deposited in a highly reproducible fashion, with easy checking by on-line monitoring; any unscheduled events are easily detected and can be fed into a supervisory monitor without human intervention. None of 
the present conventional remelting processes has this capability. More importantly, the liquid metal up to the stage of the cast ingot surface, is completely visible and can be monitored for temperature, composition, and inclusion "rafts". In this latter respect, the entire process may be used, by image analysis methods, as a giant EB button test, with the "button" being the production ingot.

Given the above advantages, what would it take for the EBCHM process to become the industry standard for clean IN718? First and foremost, we need to develop a process technology which is reliably excellent and which can be monitored to demonstrate this excellence. Present mechanical and electrical designs are clearly capable of accomplishing this aim, but the keyword is "reliably". Second, the producer must engage in development programmes with the users to make statistically-meaningful quantities of clean alloy so that the true nature of the process can be demonstrated. It cannot be overemphasized that the EBCHM advantage will lie in the removal of rare, random defects, which necessarily means that the test volumes of alloy must be large. Third, we must educate the designer and the financial comptroller to take advantage of the clean alloy production. Testing and rejection are expensive - doubly so in most of these applications since the testing can only be carried out at a very late stage in manufacture. It is possible that any added cost of EBCHM would vanish in the final component cost if we can totally capitalize on clean alloy production in the overall sequence of design and manufacture, even in the case of a low cost alloy such as IN718, and it is much more likely to be the case in the higher-cost superalloys. Where these conditions can be satisfied there is an excellent potential that $\mathrm{EBCHM}$ will become the standard route for the production of clean superalloys.

\section{Acknowledgements}

The author gratefully acknowledges the support of the Nickel Development Institute during the course of studies leading to this work. He is also grateful for the encouragement of the General Electric Aircraft Corporation in continuing the search for clean melting methods.

\section{References}

1. Joint Airworthyness Regulations, E (Engines), Civil Aviation Authority UK, 1986.

2. R.G.Menzies and C.B.Adasczik; Proc. Vacuum Metallurgy Conference, eds L Lherbier and G.K.Bhat (Pittsburgh PA, publ. TMS-AIME), 1986, 65 - 73.

3. L. Barnard, R.F.Brooks, P.N.Quested, K.C.Mills; J. Ironmaking and Steelmaking, 1993 in press.

4. C. Tornberg; Proc. International Conference on Tooling Materials, Interlaken Sept 1992, 1 - 9

also; 
P.Billgren and R Andersson; "Modern Developments in Powder Metallurgy" 1984, 17, $359-383$.

5. T. Gladman; Proc. 4th International Conference on Clean Steels, Balatonfured, 1992, publ. Inst. Metals., London UK, 3 - 24.

6. A. Mitchell; "Electric Furnace Steelmaking" 3rd Ed, ed. C Taylor, publ. ISS/AIME $1985,226$.

7. W.H.Sutton; Proc. 7th International Conference on Vacuum Metallurgy, publ. Japanese Iron \& Steel Soc, Tokyo, 1982, 2, 1420 - `1428.

8. C.H.Entriken; Electron Beam Refining, ed R Bakish, publ. Bakish Corp, Englewood,NJ, 1985, Part 1, 40 - 47.

9. S L Cockcroft, T Degawa, A. Mitchell, D W Tripp and A Schmalz; "Superalloys 92", eds S D Antolovich, publ. TMS AIME, 1992, 577 - 589.

10. A. Mitchell; Proc. 4th International Conference on Clean Steel, Balatonfured, 1992, publ. Inst. Metals UK, 588 - 594.

11. P.N.Quested, D.M.Hayes, K.C.Mills and J.D.Ellis; "Electron Beam Refining - State of the Art", cd R Bakish, publ. Bakish Corp, Englewood NJ USA, 1992, 260 - 273.

12. E Samuelsson; PhD Thesis, Dept of Metals and Materials Engineering, Univ. of British Columbia, 1985

13. J.J.deBarbadillo; Met Trans, 1983, 14^, 329 - 341.

14 S. Yamaguchi, H. Kobayashi, T. Matsumiya, S. Hayami; Mcts Techn., 1979, May, $170-175$.

15. W.H.Couts, S. Inouye, G. Saul; Technical Report AFML-TR-71-76, Airforce Materials Lab., Airforce Systems Command, Wright-Patterson AFB, Ohio, USA.

16. K. Thomas, P.J.Appleton, W.S.Wilson and M.J.Worrall; "Clean Steel 4", Metals Soc, London 1992, 308 - 325.

17. J.Radavitch; "Superalloy 718", ed. E Loria, TMS-AIME, Warrendale PA, 1989, 229 $-240$

18. M.J.Poole; Internal Report, International Nickel Co, 1988. 
SNECMA

718 SUPERALOY - LCF MINUAUN CYCUC UFE

$T=350^{\circ} \mathrm{C}-$ STRAN AMPUTUDE $=0.62 \mathrm{~F}$

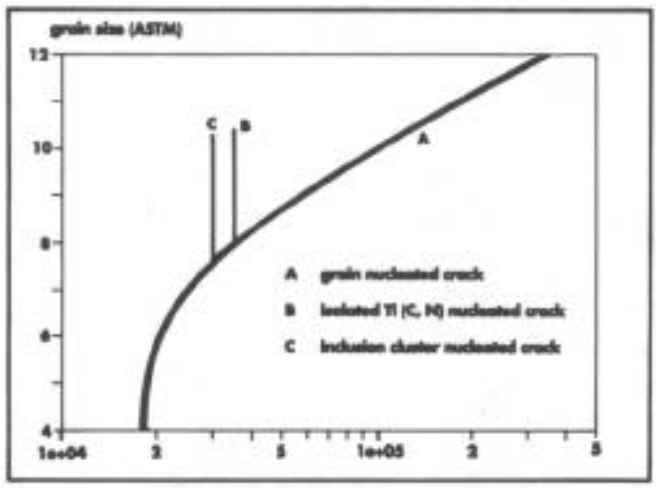

Fig 1. Fatigue behaviour of IN718, showing the importance of carbide and inclusion content (courtesy SNECMA).

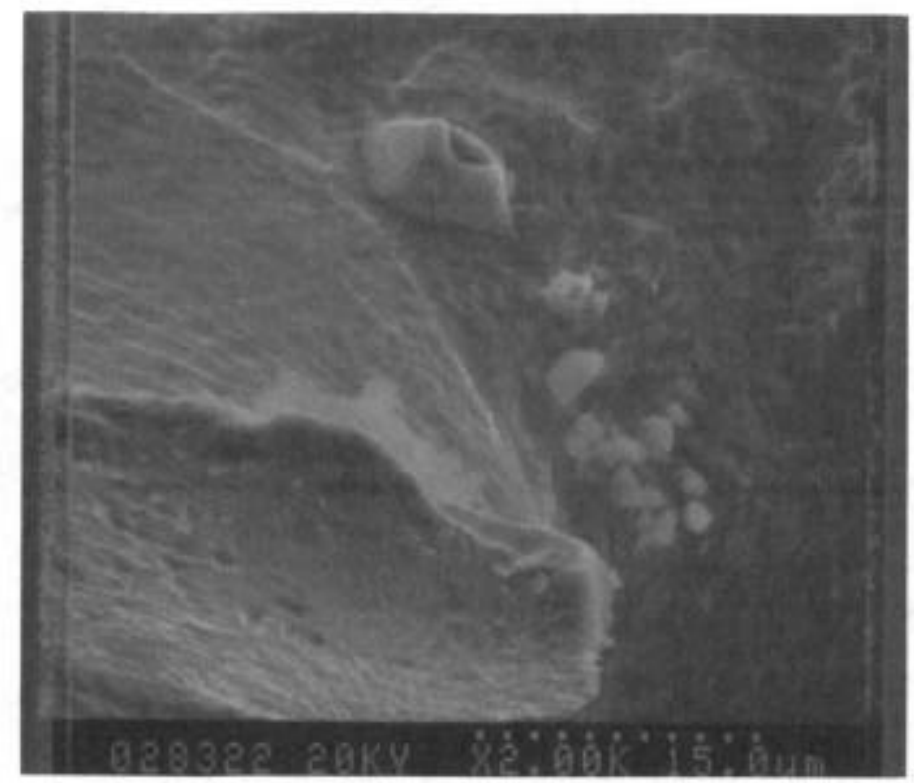

Fig 2. Alumina particles and TiN on the melting surface of an as-cast IN718 electrode. 


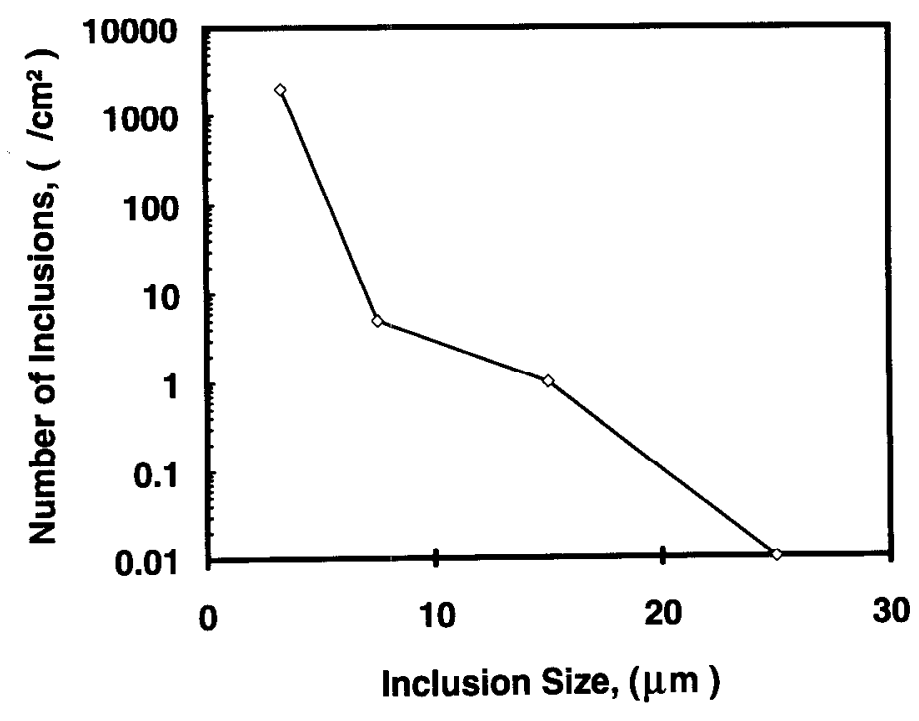

Fig 3. Typical inclusion distribution for a "clcan" steel, assessed metallographically.

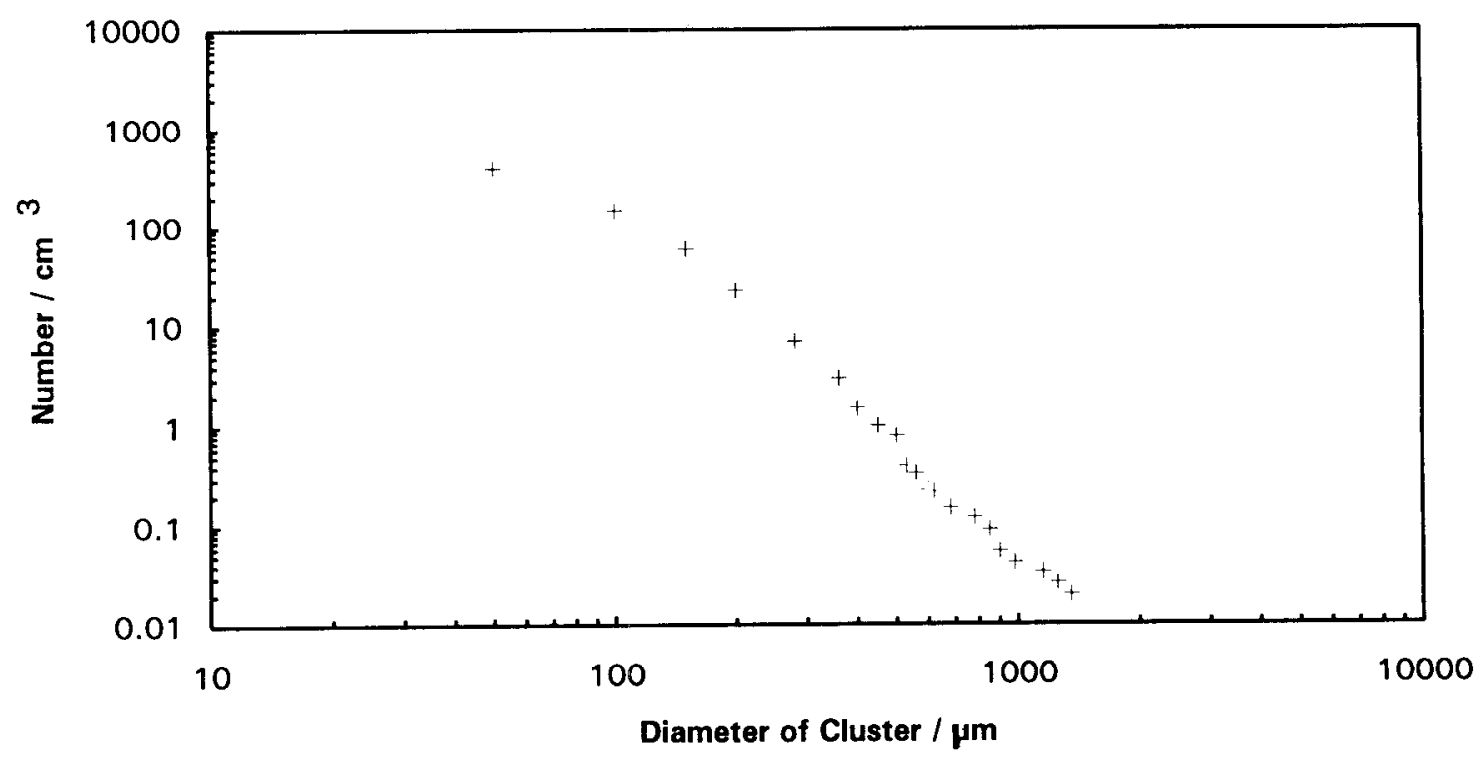

Fig 4. Typical clustering distribution of inclusions in a "clean" steel. 